\title{
Commuter's Modal Choice: A Case Study of Savar Pourashava
}

\author{
Md. Lutfur Rahman* \\ Md. Monowarul Islam *** \\ Mohammad Al Mamun ***
}

\begin{abstract}
Commuter's modal choice is a complex phenomenon in urban transportation. It is a key determinant of modern transport planning. Commuters always want to get a hold on any mode at any point of time to meet their travel demand and the selection of mode depends on various factors associated with the commuting. In Savar Pourashava, modal choice by commuters varies with commuter's socio-economic background and demographic characteristics. It also varies with the services that are provided by the various modes operating in the study area. The land use characteristics also affect the travel behavior pattern of commuters in the study area. The attitude and preference of commuters towards modes are also varied from each other. For achieving efficient and reliable transportation system in terms of modal choice of the commuters in the study area, it is essential to identity various factors affecting the travel pattern of the commuters. This research has attempted to identity these factors in modal choice and investigated over the mode that has been preferred by individual commuters and the reasons for selection of the mode. Beside this, the research has explored the relationship between land use characteristics and travel behavior pattern of the commuters.
\end{abstract}

\section{Introduction}

Commuter's modal choice is a complex phenomenon and it is one of the key determinants of recent day transportation planning. Modal choice is the process of opting "persons trips" or "freight movements" by the mode of transport (Cracknel, 2001).It considers the factors that are important to people or companies when making the decision as to which mode to use. Commuter's modal choice is also intrinsically related to land use (Lee, 1989). Interaction between land use and transportation to a greater extent dictates the commuter's modal choice and subsequently availability (Hellewell, 1983).

Transportation is not usually demanded in its own right. Few people travel simply to enjoy the journey, and trips are normally made to take advantages of opportunities that are available for particular destinations. Trips are made by people for social, recreational, educational or commercial purposes. With the exception of recreational trips, travel is not required for its own sake. It is rather a means of accomplishing some purposes. People travel not for traveling sake only but to get to their places of interest for some other activities such as working, shopping etc. Viewed from this point, travel is basically an undesirable activity. But it reduces the spatial disadvantages of separation by improving the communication between land use activities.

Dhaka, the capital of Bangladesh is now experiencing the highest concentration of population.In 1991, Dhaka's population was 6.5 million spreading over a land area of about 415 sq. km. (GOB, UNCHS and UNDP, 1993). Dhaka, as one of the most crowded mega city of the world is becoming more and more unlivable with the growth of population. As a result, people search for better living conditions around Dhaka City. They look for places, where there are sufficient

\footnotetext{
* Lecturer, Department of Urban and Regional Planning, Jahangirnagar University, Savar, Dhaka Email: lutfurju@yahoo.com

** Planning and Research Officer, Bangladesh Institute of Planners (BIP), Bangla Motor, Dhaka Email: monowarurp@gmail.com

*** Assistant Project Officer, DIPECHO Project, Islamic Relief, Bangladesh Email: mamunurpju@gmail.com
} 
employment opportunities and better communication facilities with Dhaka City. People choose Savar as their living place, because of its good communication with Dhaka and its surrounding areas by transportation network.

Savar as a satellite town has opportunities of employment within and outside the pourashava area. In the northern side of Savar, one important industrial zone known as Savar Export Processing Zone (EPZ) is located. A large portion of people go to Dhaka and its surrounding areas for different purposes such as business, service, work, shopping, recreation, school etc. So, the Transportation network and modal availability play a significant role in trip generation to communicate with Dhaka and its surrounding areas. In Savar, various modes e.g. walk, rickshaw, auto-rickshaw, bus, tempo and human hauler are operating to communicate within and outside its boundary. The modal choice of the people varies according to their age, sex, income, trip purposes, distance and time. Moreover, the degree of its provisioning and 'modus operandi' to serve the public exerts a major influence on the living of the concerned community (Hellewell, 1983). Without physical access to jobs, health, education and amenities, quality of life can not be improved (World Bank, 1996). Efficient, accessible network along with modal availability and comfort are the prerequisites for better transport services. Thus modal choice is a part of transport system.

Savar is situated at a distance of about $29 \mathrm{~km}$ to the north-west of Dhaka City on the DhakaAricha highway. Savar Upazila has an area of 280.13 sq. km of which the Savar Pourashava is $16.67 \mathrm{sq}$. km. It consists of 9 wards and has a population of 161600 with a density of 9694 persons per sq $\mathrm{km}$ (Field survey, 2006). The study area enjoys the distinction of having various activities such as culture, education, commerce, industry and above all it provides facilities for the accommodation of people. The transport system consists of both motorized and non-motorized modes and the people of the study area choose these modes for different trip purposes. Since the people of this area are involved in various activities within the inner zone (the peoples are involved in activities with in the study area) and outer zone (the peoples are involved in activities outside the study area), transportation is the key element for better communication to the inner and outer zone.

Savar is well communicated by the road transport with its inner and outer area. The intention of the trip makers for selecting mode is different with respect to their income level. The most common trip purposes of the people of the study area are journey to work, business and nonbusiness. Their travel behavior and travel pattern is different from each other. Therefore, the commuter's modal choice is an important consideration for trip making purpose. The modes for passenger's trips are not adequate in the study area in terms of people's attitudes, perception, and utility preferences.

Depending on the activity pattern of the study area, three categories of trips are found that are made by the commuters, e.g. home based work trips or trips between home and workplace, other trips between home and shop, educational establishment and social activities and non-home based trips. The population of the study area is increasing day-by-day but the land use is developing in an unplanned way and in no consistency with transport infrastructure. Since different income groups live in a mixed residential environment, they face a serious problem in selecting transport modes for their trips. Lower income group usually prefer cheap public transport and middle, higher middle or higher income groups mostly prefer private transport or luxury public transport.

\section{Objectives and Methodology}

The main objective of the research is to identify the factors that influence the modal choice by the commuters and to explore the relationship between land use system and travel behavior of the study area. Literature review was conducted to conceptualize the research problem, and data from both primary and secondary sources were collected for this study. Primary data was collected through reconnaissance survey, personal interview on socio-economic characteristics of an 
individual trip maker. In this study, sample of 660 individuals were taken for collecting travel data and stratified random sampling technique was used. After sorting and screening (such as incomplete questionnaire, invalid data etc.), only 550 samples were considered for further analysis. So the result may tend to be indicative of travel behavior in Savar Pourashava rather than definitive outcome. Secondary data include information on demographic characteristics of the people (such as age, sex, total population, employment etc), attraction data and different kinds of maps of the study area and they were collected from various institutions such as Savar Pourashava, BBS (Bangladesh Bureau of Statistics) and LGED (Local Government Engineering Department) etc.

\section{Road Transport System of the Study Area}

Road transport network is an important element of urban services. The internal road transport system plays a vital role in respect of better communication within and outside of the study area and also for different trip making purposes such as business, service, work, school, shopping, social, religious, recreation and medical purposes. In the study area, RHD (Roads and Highways Department) road (Dhaka-Aricha highway) covers 0.005 square kilometer. The Pourashava main road covers 0.017 square kilometer and the Pourashava local road cover 0.097 square kilometer (Field Survey, 2006). Savar is also well linked with Dhaka and its surrounding areas by DhakaAricha highway and Savar-Kaliakair Road. For better communication with Dhaka and its surrounding area (such as Savar EPZ), the trip makers make 17.38 percent trip at Motijheel, 14.12 percent trip at Tejgaon and 21.25 percent trip at Savar EPZ (Field survey, 2006). In Savar Pourashava, both motorized and non-motorized vehicles are operated which play a vital role to communicate with Dhaka and its surrounding areas. List of motorized and non-motorized vehicles, which are operated in the study area are shown in Table 1.

Table 1: Types of motorized and non-motorized vehicles.

\begin{tabular}{|c|c|}
\hline Broad vehicle group & Operating modes \\
\hline Non-Motorized Vehicle (NMT) & Walk \\
\cline { 2 - 2 } & Rickshaw \\
\hline \multirow{2}{*}{ Motorized Vehicle (MT) } & Bus \\
\cline { 2 - 2 } & Human haulers \\
\cline { 2 - 2 } & Tempo \\
\cline { 2 - 2 } & Auto rickshaw \\
\hline
\end{tabular}

Source: Field Survey, 2006.

The share of non-motorized vehicles in the study area is 40.86 percent. Non-motorized vehicle includes walk, rickshaw and walk plus rickshaw of which rickshaw is the dominating modes in the study area, which make about $28.23 \%$ trips (Field survey, 2006). Rickshaw is the dominating mode in the study area, because there is no alternative mode to make trip for different purposes. The average trip time for rickshaw is 14 minutes. The average trip distance for rickshaw is $2 \mathrm{~km}$. (Field Survey, 2006). The distribution of daily trips by different modes in Savar Pourashava area is shown in Table 2. 
Table 2: Distribution of daily trips by different modes in Savar Pourashava.

\begin{tabular}{|c|c|c|c|c|}
\hline Broad vehicle group & Mode & Daily trips & $\begin{array}{l}\text { Average trip distance } \\
\text { (k.m.) }\end{array}$ & $\%$ of total trips \\
\hline \multirow{3}{*}{$\begin{array}{l}\text { Non-Motorized vehicle } \\
\text { (NMT) }\end{array}$} & Walk & 55.00 & 1.00 & 8.17 \\
\hline & Rickshaw & 190.00 & 2.00 & 28.23 \\
\hline & Walk + Rickshaw & 30.00 & 1.50 & 4.46 \\
\hline \multicolumn{2}{|c|}{ Total NMT } & 275.00 & 1.50 & 40.86 \\
\hline \multirow{2}{*}{ Mixed (NMT+ MT) } & Walk +Bus & 22.00 & 2.00 & 3.27 \\
\hline & Rickshaw + Bus & 51.00 & 17.00 & 7.58 \\
\hline \multicolumn{2}{|c|}{ Total Mixed } & 73.00 & 9.50 & 10.85 \\
\hline \multirow{4}{*}{ Motorized vehicle (MT) } & Bus & 215.00 & 18.00 & 31.95 \\
\hline & Human haulers & 18.00 & 21.00 & 2.67 \\
\hline & Tempo & 49.00 & 3.00 & 7.28 \\
\hline & Auto rickshaw & 43.00 & 5.00 & 6.39 \\
\hline \multicolumn{2}{|c|}{ Total MT } & 325 & 12.00 & 48.29 \\
\hline \multicolumn{2}{|c|}{ Total } & 673.00 & 23.00 & 100.00 \\
\hline
\end{tabular}

Source: Field Survey, 2006.

\section{Land Use of the Study Area}

Savar Pourashava has a mixed land use comprising residential, commercial, industrial, agricultural and institutional land use, open space, water bodies and road network. The mixed type of land use is seen almost all over the wards in the study area. The study area consists of 9 wards and their land use is totally different from each other. The total area of Savar Pourashava is16.67 square kilometer of which $54.85 \%$ is residential, $4.56 \%$ is commercial, $2.08 \%$ industrial, $24.55 \%$ is agricultural, $2.93 \%$ is institutional, $0.67 \%$ road network and others is $10.36 \%$ e.g. open space and water bodies ( Field Survey, 2006). Percentage of ward wise different land use of the study area is given below.

Table 3: Percentage of Ward wise land uses of the Pourashava.

\begin{tabular}{|c|c|c|c|c|c|c|c|}
\hline \multirow[b]{2}{*}{ Ward No. } & \multicolumn{6}{|c|}{ Percentage of land uses } & \multirow[b]{2}{*}{$\begin{array}{l}\text { Others (open } \\
\text { space, pond and } \\
\text { water bodies }\end{array}$} \\
\hline & 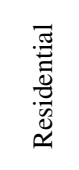 & 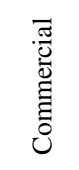 & 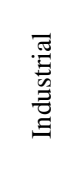 & 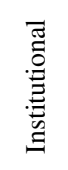 & 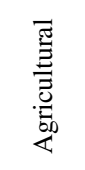 & 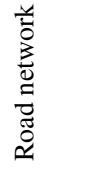 & \\
\hline 01 & 44.18 & -- & -- & 1.39 & 32.76 & 0.49 & 21.18 \\
\hline 02 & 81.44 & 14.78 & 0.29 & 2.32 & -- & 1.17 & -- \\
\hline 03 & 82.98 & 6.39 & 0.41 & 2.30 & 7.39 & 0.53 & -- \\
\hline 04 & 65.40 & 28.46 & -- & 4.80 & -- & 1.34 & -- \\
\hline 05 & 83.07 & 7.82 & -- & 7.56 & -- & 1.55 & -- \\
\hline 06 & 61.12 & 0.47 & 10.39 & 8.25 & 15.73 & 0.62 & 3.42 \\
\hline 07 & 59.53 & 8.11 & 0.24 & 3.09 & 17.47 & 0.67 & 10.89 \\
\hline 08 & 40.66 & 5.97 & 0.92 & 1.92 & 41.22 & 0.58 & 8.73 \\
\hline 09 & 49.24 & -- & 4.38 & 1.13 & 30.96 & 0.70 & 13.59 \\
\hline
\end{tabular}

Source: Field Survey, 2006. 


\section{Factors Affecting Modal Choice}

Modal choice in the study area is related with people's socio-economic and demographic characteristics, level of service (LOS) of the transport modes e.g. travel time, cost, accessibility of the modes and travel attributes of different modes (e.g. convenience, comfort, privacy, reliability, safety and security). These are illustrated below.

Relative Level of Service (LOS) of the Transport Modes: Relative LOS is consisted of travel time, travel cost, accessibility of the modes and travel attributes of modes. The findings from survey are discussed below.

Travel Time, Cost and Distance of Different Modes: According to different chosen modes detail analysis of journey by trip time, cost and distance were made. Considering walking trips, the average trip time was five minutes and the average trip distance was one kilometer, where there was a very short trip of half kilometer and a long trip of three kilometers.

For rickshaw, the average trip time was fourteen minutes and the average trip distance was two kilometers with an average trip cost of taka eight. Rickshaws were mostly used for internal and short trips between fares of taka three to fifteen. For tempo trips, the average trip time was twenty minutes with an average trip distance of three kilometers and an average trip cost of six taka.

For auto-rickshaw, the average trip time was twenty five minutes with an average trip distance of five kilometers and an average trip cost of taka thirty. It has been found that people do not make a very short trip by auto-rickshaw as its minimum fee was very high-taka twenty.

For bus, the average trip time was nearly an hour with an average trip distance of eighteen kilometers and an average trip cost of taka fifteen. Incase human hauler, the average trip time was thirteen minutes with an average trip distance of twenty one kilometers and an average trip cost of taka ten.

Accessibility of the Modes: In the study area, there were no modes that maintain the time table for departure and arrival. As a result, sometimes, the service holders, administrative employees and students could not reach their destination timely. There were no competing modes, which was more reliable than another. Although, bus is the only mode for the trip makers for long and short distance purposes but the services are very poor and it can not meet the demand of travelers of the study area.

Travel Attributes of Modes: Respondents were questioned about the different attributes of the different modes in Savar Pourashava. The accessibility of rickshaw was the highest that is $39.10 \%$ with a minimum waiting time which reflects the present daily trip distribution in Savar Pourashava. Accessibility for bus, it was $21.82 \%$ and for tempo, it was $12.91 \%$, for auto-rickshaw, it was $10.35 \%$ and for human haulers, it was $15.82 \%$, where as, high waiting time for autorickshaw was the highest, $37.64 \%$.

\section{Trip Types}

Trip types include factors, like trip purpose, trip distance, traveling hours of the day and frequency of traveling. These are illustrated below.

Trip Purpose and Distance: In the study area, most of the trips were generated for service purpose that was $39.07 \%$ and the business was in the second position that was $28.68 \%$ (Field Survey, 2006). The average trip distance for service and business were fourteen and thirteen kilometers respectively. People of the study area also generated trips for weekly basis such as shopping, social, recreational, religious and medical and from all types of trips, people generated highest trip for shopping purpose that was $27.94 \%$.

Travel Hours of the Day: The demand for travel was not evenly distributed throughout the day but tended to be concentrated at certain peak periods of the day. These were "morning peak" (between 7:00 AM to 10:00AM), "mid-day peak" (between 1:00PM to 3:00 PM) and "evening 
peak" (between 4:00PM to 7:00 PM). The existing services can not meet the travel demand of the people of the study area who travel for their different purposes at different times.

Frequency of Traveling: In the study area, it is found that $95.46 \%$ respondents of the study area was made trips daily and only $4.54 \%$ was made trips weekly basis for their different purposes.

\section{Characteristics of Trip Makers}

Again, characteristics of trip makers, such as age, sex, income, vehicle ownership pattern and occupational status also influence the modal choice at individual level. Following are the findings from field survey conducted in 2006 in Savar Pourashava.

Age and Sex: Considering age of the trip makers, middle aged people usually prefer bus and rickshaw mostly for their trip within and outside of the study area. It is found that the use of bus was mostly avoided by the aged and young children due to lack of safety and inconvenience. On the other hand, it is observed that males travel more trips $(61.11 \%)$ than females $(38.89 \%)$. The average travel time of female was higher in respect of a trip of male that was nearly twenty three and a half minutes, where as the average travel time for male was nearly twenty one and a half minutes. The average trip distance for male was $9.82 \mathrm{~km}$. and for female that was $8.34 \mathrm{~km}$. Most of the female avoided bus service mostly because of less convenience, privacy, comfort and its poor service quality. Since, in the study area, there was no alternative mode for female to choose mode for their trip purposes, they used this bus service against their will.

Income: Low and middle income people traveled more number of trips $(74.29 \%)$ than high income people $(25.71 \%)$. These income groups used rickshaw for their internal trip making purposes and used bus for traveling purposes within and outside the Pourashava area. The low income groups usually preferred those modes, which had minimum cost rather than comfort, privacy and security. But most of the middle and higher groups were intended to use the modes that were more comfortable, safe and secure negotiating with cost. The average trip time for middle income groups was high that was twenty six minutes compared to low and middle income groups that were twenty four and twenty two minutes respectively. But the average trip distance for high income group was high that was sixteen $\mathrm{km}$. compared to middle and low income groups that were eleven and ten $\mathrm{km}$. respectively.

Occupational Status: Modal choice also varies with social status i.e. employee, employer, student, dependent children, housewife etc. Administrative employees were much more likely to use private transport than low income groups and workers. Public transport, being the cheaper mode, are available to attract the lower income groups, i.e. students, housewife and other low wage earner of different job groups. But due to unavailability of modes in the study area, they faced a serious problem in respect of selecting modes for their trip purposes. Life style was another reason, which plays an important role for modal choice. More educated persons were likely to use the modes, which were comfortable for them rather than thinking the cost of travel although their income level was not so high. There were also peoples whose income was high but they liked to use public transport saving the travel cost.

\section{Trip Generation, Distribution and Modal Choice}

\section{Trip Generation and Distribution}

Modal choice depends on how many trips are generated in the region and distributed within and outside the regions. There are various modes used by respondents, such as rickshaw, autorickshaw, tempo, bus and human haulers operating in the study area that are considered as motorized and non-motorized (Table 4). 
Table 4: Generation of trips by different modes in the study area.

\begin{tabular}{|c|c|c|}
\hline Broad vehicle group & Modes & Daily trips \\
\hline \multirow{3}{*}{ Non-Motorized vehicle (NMT) } & Walk & 55 \\
\hline & Rickshaw & 190 \\
\hline & Walk + Rickshaw & 30 \\
\hline \multicolumn{2}{|l|}{ Total NMT } & 275 \\
\hline \multirow[t]{2}{*}{ Mixed (NMT+ MT) } & Walk +Bus & 22 \\
\hline & Rickshaw + Bus & 51 \\
\hline \multicolumn{2}{|l|}{ Total Mixed } & 73 \\
\hline \multirow{4}{*}{ Motorized vehicle (MT) } & Bus & 215 \\
\hline & Human hauler & 18 \\
\hline & Tempo & 49 \\
\hline & Auto rickshaw & 43 \\
\hline \multicolumn{2}{|l|}{ Total MT } & 325 \\
\hline \multicolumn{2}{|l|}{ Total } & 673 \\
\hline
\end{tabular}

Source: Field Survey, 2006.

Trips are distributed to Motijheel, Tejgaon and Savar EPZ and within Savar Pourashava. Distribution of trips throughout the region is shown in figure 1.

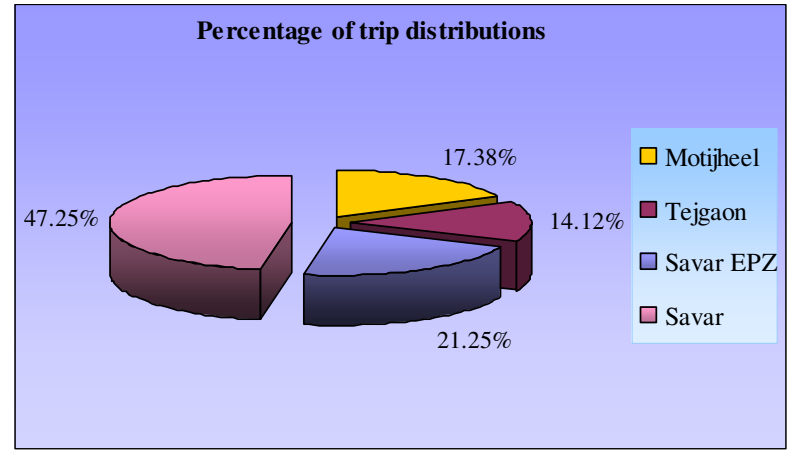

Fig. 1: Percentage of trip distribution for different destinations.

\section{Modal Choice}

Modal choice of the respondents of the study area is analyzed based on the selection criteria for different modes, modal share (e.g. walk, rickshaw, auto-rickshaw, tempo, bus and human haulers that are operating in the study area), travel behavior of the respondents for the frequent selection of mode by the respondents, attitudes towards selecting a mode or maximum acceptable criteria, complain against the selected mode, opinion on safety about traveling by the selected mode and reasons behind selecting a particular mode by the respondents. In the following section, these types of factors are discussed in details.

\section{Selection Criteria for Different Modes}

Selection criteria are related with travel time, cost and distance that are different for different modes. The respondents choose those modes whose travel time and cost are acceptable to them.

Walking: Respondents were questioned about their opinion of the maximum and minimum attribute values for selecting a particular mode. In case of walking, people are willing to travel a 
maximum distance of three kilometers of walk trips where $34 \%$ of people preferred 1.5 kilometers and $29.64 \%$ of people preferred 1.0 kilometers. In case of travel time, people were willing to travel a maximum travel time of half an hour where $30.91 \%$ of people preferred 25 minutes and $27.82 \%$ of people preferred 20 minutes.

Rickshaw: In case of rickshaw trips, people were willing to pay a maximum fare of taka fifteen where $29.10 \%$ of people preferred taka ten and $25.45 \%$ percent of people preferred taka twelve. For distance, most of the people were willing to select a rickshaw for a minimum distance of 1.5 kilometer and a maximum of 6.0 kilometers. For times, most of the people are willing to select a rickshaw for a minimum time of eight minutes and a maximum travel time of twenty five minutes.

Auto-rickshaw: In case of auto-rickshaw trips, people were willing to pay a maximum fare of taka fifty where $30.91 \%$ of people preferred taka forty five and $28.18 \%$ of people preferred taka forty. For distance, most of the people were willing to select an auto-rickshaw for a minimum distance of six kilometer and a maximum of twelve kilometers. For times, most of the people are willing to select an auto-rickshaw for a minimum time of fifteen minutes and a maximum travel time of thirty minutes.

Tempo: In case of tempo trips, people were willing to pay a maximum fare of taka ten where $26 \%$ of people preferred taka nine and $22.36 \%$ of people preferred taka eight. For distance, most of the people are willing to select a tempo for a minimum distance of two kilometer and a maximum of eight kilometers. For times, most of the people were willing to select a tempo for a minimum time of eight minutes and a maximum travel time of twenty five minutes.

Bus: In case of bus trips, people were willing to pay a maximum fare of taka twenty five where $28.18 \%$ of people preferred taka twenty and $26.36 \%$ of people preferred taka twenty two. For distance, most of the people are willing to select a bus for a minimum distance of two kilometer and a maximum of twenty six kilometers. For times, most of the people were willing to select a bus for a minimum time of twelve minutes and a maximum travel time of forty minutes.

Human Hauler: In case of human hauler trips, people were willing to pay a maximum fare of taka twenty where $29.64 \%$ of people preferred taka sixteen and $26.36 \%$ of people preferred fourteen. For distance, most of the people were willing to select a human hauler for a minimum distance of two and a half of a kilometer and a maximum of twenty kilometers. For times, most of the people were willing to select a human hauler for a minimum time of ten minutes and a maximum travel time of forty minutes.

\section{Modal Shares in the Study Area}

Different kinds of mode are operating in the study area. People are making trips by using these types of mode for various purposes. At the time of survey, the respondents are asked about their choice of modes that are used by them to make a trip for their particular purposes. A true picture about modal share of the study area is found from the survey results (Figure 2).

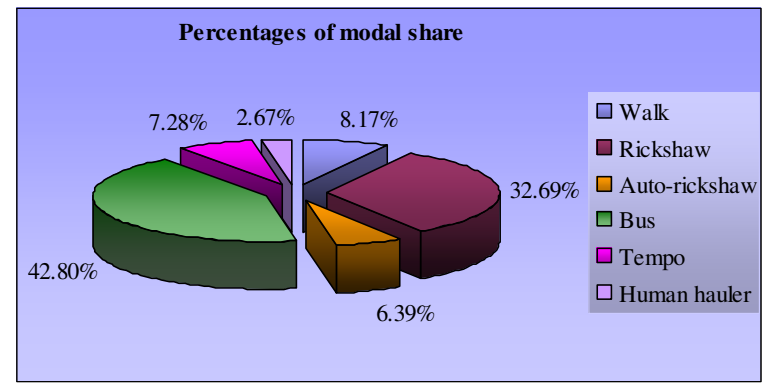

Fig. 2: Percentages of modal shares in the study area.

In the study area, it is found that rickshaw is a dominant mode that is used by the respondents to make a daily trip for different purposes, such as business, service, school and work. The weekly 
trips for various purposes, such as shopping, social, recreation, religious and medical are also made by rickshaw within the study area. The reason for selecting rickshaw is the availability of it and no other alternative modes are operating so frequently within the area. Since rickshaw is the only mode to make trip by all income groups (low, middle and high) in the study area, it is not a matter of concern for analyzing the factors of selecting the mode of rickshaw by the people of the study area. There is, however, variation of selecting modes by the respondents when they make trips for particular purposes to reach different destinations inside and outside the study area. Although there are different modes operating in the study area to communicate with outside the region, bus is the highest selected mode to make a particular trip by the respondents. So it is a matter of concern to discuss their opinions about bus trips. Their opinions are stated in the following sections.

\section{Frequency, Purposes and Traveling Distance, Time and Cost}

The survey information is presented in Table 5. More than $61 \%$ of respondents used bus once a day, mostly for their work trips. The respondents usually made trips by bus for different purposes, such as business, service, school and work. Out of total 288 trips that are made by bus, 95 trips are made for business purpose, 111 and 35 trips are made respectively for service and school purposes and 47 trips are made for work purposes. More than $37 \%$ of the frequently used bus trips distances were up to fifteen kilometers and $63.64 \%$ of them were not more than forty minutes. In the case of bus trips, $37.15 \%$ percent users paid a fare between taka ten to fifteen, $31.94 \%$ paid above twenty taka, $23.17 \%$ paid between taka fifteen to twenty, $4.17 \%$ paid between taka five to ten and $3.13 \%$ paid below five taka.

Table 5: Frequency of travel by bus.

\begin{tabular}{|c|c|c|c|c|}
\hline \multicolumn{2}{|c|}{ Frequency of trips } & No. of respondent's & Percentage & Total $(\%)$ \\
\hline \multirow[t]{5}{*}{ Daily } & Once a day & 145 & 61.44 & \multirow{5}{*}{89.40} \\
\hline & Twice a day & 42 & 17.80 & \\
\hline & 3 times a day & 20 & 8.47 & \\
\hline & 4 times a day & 04 & 1.69 & \\
\hline & 5 times a day & -- & -- & \\
\hline \multirow[t]{2}{*}{ Weekly } & 2 to 3 times a week & 16 & 6.78 & \multirow[b]{2}{*}{10.60} \\
\hline & 4 to 5 times a week & 09 & 3.82 & \\
\hline \multicolumn{2}{|l|}{ Total } & 236 & 100.00 & 100.00 \\
\hline
\end{tabular}

Source: Field Survey, 2006

\section{Attitude towards Selecting a Bus Trip}

Attitude towards selecting a bus trip by the respondents of the study area is discussed based on three criteria that are maximum acceptable travel distance, maximum acceptable travel time and maximum acceptable travel cost for frequent use of daily trips made by the respondents of the study area.

Travel Distance, Time and Cost: Respondents were questioned about their attitude towards selecting a bus trip on the basis of maximum acceptable criteria. For distance, most of the people are willing to select a bus for a maximum distance of twenty four kilometers. For times, most of the people are willing to select a bus for a maximum travel time of forty minutes. Almost $27.97 \%$ would select a bus trip to a maximum acceptable fare of taka twenty.

Complaints against Bus Trips: Buses are not above the demerits. Almost ninety percent respondents expressed their opinion that there are more than one complains against bus as a travel mode. More than eighty respondents have complain "bus driver do not follow the traffic rules" and 
"bus driver dive bus recklessly" during plying on the roads. About twenty six percent respondents have complain "bus are not available during certain hours" and sixty three of respondents have complains "bus fare is too high".

Opinion on Safety about Traveling by Bus: Considering safety aspects, $30.30 \%$ of respondents feel traveling by bus within the study area and from the study area to different destinations were "very unsafe" and $20.60 \%$ of respondents feel "unsafe" and 56.1\% respondents feels "safe".

Reasons behind Selecting a Bus Trip for General Purpose: Despite some complaints, many respondents had given their opinion in favor of bus for selecting them as a travel mode. Among these, $97.63 \%$ respondents had expressed that rickshaw was preferable to them in long distance travel, $91.83 \%$ had given their opinion in favor of "no other alternatives", $89.05 \%$ had given their opinion in favor of "more convenient", $86.40 \%$ had given their opinion in favor of "less waiting time" and $84.15 \%$ had given their opinion in favor of "more reliable". Next influencing reasons were security, easy access, less travel time and greater safety. The information can be observed in Table 6.

Table 6: Reasons behind selecting a bus trip for general purpose.

\begin{tabular}{|l|c|}
\hline Type of reasons & Percentage \\
\hline More safe & 51.78 \\
\hline Less travel time & 63.16 \\
\hline More reliable & 84.15 \\
\hline More secured & 78.46 \\
\hline Preferable in long distance & 97.63 \\
\hline No other alternatives & 91.83 \\
\hline Less waiting time & 86.40 \\
\hline More convenient & 89.05 \\
\hline Easy access & 76.18 \\
\hline
\end{tabular}

Source: Field Survey, 2006.

\section{Future Prediction of Trips for the Study Area}

Gross classification analysis method is used to predict the future number of trips that will be produced in the study area. By estimating the future number of households and applying the calculated trips, the future number of trips that will be generated in the study area is calculated. The present trips status made by different modes operating in the study area according to household size and number are related. The percentile distribution of households for each mode according to household size is given in Table 7 .

Table 7: Percentile distribution of household for each mode according to household size.

\begin{tabular}{|c|c|c|c|c|c|c|}
\hline Modes & Walk & Rickshaw & Bus & Auto rickshaw & Tempo & $\begin{array}{c}\text { Human } \\
\text { hauler }\end{array}$ \\
\hline 2 & 0.005 & 0.005 & 0.004 & 0.004 & 0.005 & 0.004 \\
\hline 3 & 0.007 & 0.020 & 0.024 & 0.004 & 0.004 & 0.005 \\
\hline 4 & 0.009 & 0.100 & 0.167 & 0.015 & 0.013 & 0.020 \\
\hline 5 & 0.011 & 0.033 & 0.204 & 0.009 & 0.011 & 0.018 \\
\hline $5+$ & 0.007 & 0.035 & 0.218 & 0.009 & 0.011 & 0.020 \\
\hline
\end{tabular}

Source: Field Survey, 2006. 
The population of Savar Pourashava is 1,61,600. As the sample size represents the total population, the total population of Savar Pourashava can be distributed by number of households against their modal choice.

Table 8: Distribution of total population of Savar Pourashava.

\begin{tabular}{|c|c|c|c|c|c|c|}
\hline Modes household size & Walk & Rickshaw & Bus & $\begin{array}{c}\text { Auto } \\
\text { rickshaw }\end{array}$ & Tempo & $\begin{array}{c}\text { Human } \\
\text { hauler }\end{array}$ \\
\hline 2 & 808 & 808 & 646 & 646 & 808 & 646 \\
\hline 3 & 1131 & 3232 & 3878 & 646 & 646 & 808 \\
\hline 4 & 1454 & 16160 & 26987 & 2424 & 2101 & 3232 \\
\hline 5 & 1778 & 5333 & 32966 & 1454 & 1778 & 2909 \\
\hline $5+$ & 1131 & 5656 & 35229 & 1454 & 1778 & 3232 \\
\hline
\end{tabular}

Source: Field Survey, 2006.

The trip rate is calculated by trips that are made by different modes divided by the household number with regard to particular modes. The trip rates for different kinds of modes are given in Table 9.

Table 9: Trip rates for different kinds of modes.

\begin{tabular}{|c|c|c|c|c|c|c|}
\hline Trip rates household size & Walk & Rickshaw & Bus & $\begin{array}{c}\text { Auto } \\
\text { rickshaw }\end{array}$ & Tempo & $\begin{array}{c}\text { Human } \\
\text { hauler }\end{array}$ \\
\hline 2 & 1.67 & 2.33 & 1.50 & 1.50 & 2.33 & 0.50 \\
\hline 3 & 2.00 & 2.27 & 1.15 & 1.50 & 2.00 & 0.67 \\
\hline 4 & 2.60 & 2.05 & 0.74 & 1.38 & 2.14 & 0.45 \\
\hline 5 & 2.80 & 1.94 & 0.88 & 2.80 & 1.67 & 0.60 \\
\hline $5+$ & 3.00 & 2.11 & 0.87 & 2.40 & 2.17 & 0.36 \\
\hline
\end{tabular}

Source: Field Survey, 2006.

The number of households is forecasted for different kinds of modes in the study area according to household size. As per the information collected from Savar Pourashava, the number of households in the study area in 2001 was 15,593 and in 2005 it was 21,297. Using the information, probable rate of increase in a certain year was determined and the rate of increase of household number was found to be 0.06 . The forecasted number of households for all modes is given in Table 10 .

Table 10: Forecasted number of households for all modes in 2011.

\begin{tabular}{|c|c|c|c|c|c|c|}
\hline $\begin{array}{l}\text { Forecasted no. of HH } \\
\text { household size }\end{array}$ & Walk & Rickshaw & Bus & $\begin{array}{c}\text { Auto } \\
\text { rickshaw }\end{array}$ & Tempo & $\begin{array}{c}\text { Human } \\
\text { hauler }\end{array}$ \\
\hline 2 & 1082 & 1082 & 866 & 866 & 1082 & 866 \\
\hline 3 & 1516 & 4331 & 5197 & 866 & 866 & 1082 \\
\hline 4 & 1948 & 21654 & 36163 & 3248 & 2815 & 4331 \\
\hline 5 & 2383 & 7146 & 44174 & 1948 & 2383 & 3898 \\
\hline $5+$ & 1516 & 7579 & 47207 & 1948 & 2383 & 4331 \\
\hline
\end{tabular}

Source: Field Survey, 2006.

Finally, the future predicted total trip by all kinds of modes of the study area is obtained by multiplying the trip rates and forecasted numbers of households for the year of 2011. The result of prediction for all types of trips that are made by the different operating modes in the study area is shown in Table 11. 
Table 11: Future predicted total trips for 2011 by different modes.

\begin{tabular}{|c|c|c|c|c|c|c|c|}
\hline $\begin{array}{l}\text { Forecasted } \\
\text { no. of trips } \\
\text { household size }\end{array}$ & Walk & Rickshaw & Bus & $\begin{array}{c}\text { Auto } \\
\text { rickshaw }\end{array}$ & Tempo & $\begin{array}{c}\text { Human } \\
\text { hauler }\end{array}$ & $\begin{array}{c}\text { Total } \\
\text { trips }\end{array}$ \\
\hline 2 & 1807 & 2521 & 1299 & 1299 & 2521 & 433 & 9880 \\
\hline 3 & 3032 & 9831 & 5977 & 1299 & 1732 & 725 & 22596 \\
\hline 4 & 5065 & 44391 & 26761 & 4482 & 6024 & 1949 & 88672 \\
\hline 5 & 6672 & 13863 & 38873 & 5454 & 5099 & 2339 & 72300 \\
\hline $5+$ & 4548 & 15992 & 41070 & 4675 & 5171 & 1559 & 73015 \\
\hline Total & 21124 & 86598 & 113980 & 17209 & 20547 & 7005 & 266463 \\
\hline
\end{tabular}

Source: Field Survey, 2006.

From the prediction of future trip generation of the study area, it can be said that the existing modal options and its service facilities will not be able to meet the travel demand of the study area. The existing transport infrastructure facilities would also not support for introducing modal options in the future. Because of introducing more modes in the study area in future, it will also create various traffic problems on the road transport system of the study area especially traffic congestion.

A comparison can also be made after future prediction of trips of different modes with their present trip status which is calculated by multiplying the present household number and the present trip rate. From this comparison, the percentile of increase of trips in future is found by different modes in the study area. The percentile of increase of trips after prediction by different modes is given in Table 12 .

Table 12: Percentile increase of trips after prediction by different modes.

\begin{tabular}{|l|c|c|c|c|c|c|c|}
\hline Modes household size & Walk & Rickshaw & Bus & $\begin{array}{c}\text { Auto } \\
\text { rickshaw }\end{array}$ & Tempo & $\begin{array}{c}\text { Human } \\
\text { hauler }\end{array}$ & $\begin{array}{c}\text { Total } \\
\text { trips }\end{array}$ \\
\hline Total present trips & 15762 & 64623 & 85058 & 12844 & 14498 & 5227 & 198017 \\
\hline Total predicted trips & 21124 & 86598 & 113980 & 17209 & 20547 & 7005 & 266463 \\
\hline $\begin{array}{l}\text { Percentage of increase of } \\
\text { trips }\end{array}$ & 34.02 & 33.99 & 34.00 & 33.98 & 41.72 & 34.01 & 34.57 \\
\hline
\end{tabular}

Source: Field Survey, 2006.

The increase of trips made by walk and rickshaw will create tremendous pressure on internal road infrastructure and traffic management system. In the study area, there is no adequate footpath beside the roads for pedestrian movement and some road widths are also inadequate for passing two rickshaws at a time. As a result, it will create traffic jam and loss of travel time. For this impact on travel time, trip makers do not reach their destinations timely. There is a tendency of haphazard growth of vehicle stands in respect of motorized and non-motorized vehicles which will also create traffic jam in the study area. It will hamper smooth flow of traffic.

\section{Application of Models for Modal Choice}

Savar as a Pourashava nearby Dhaka City plays an important role to accommodate large number of people, which includes the original inhabitants and the people who migrate from different district for different purposes, like business, service and work. Since people wants to live near to the capital, they desire good communication and other urban facilities. Everyday a large number of trips are generated from this area. The research applied gravity model for finding out the trip 
distributions to different destinations and modal split model for determining the utility of each mode.

\section{The Gravity and Logit models}

The gravity model is used to identify the daily trip distribution pattern of Savar Pourashava. The daily trips that are produced in the Savar Pourashava are distributed among different zones. Although trips are distributed among different zones, the zones where major trips are destinated, are considered in the gravity model. The zones are Motijheel, Tejgaon, and Savar EPZ. In the gravity model, distance and measures of attraction of different zones for trips of specified purpose are considered to find out the trip distribution pattern of Savar urban area. The total trips that are produced in the study area are also considered for specified purpose. On the other hand, the logit model is applied to predict the percentage of individuals who will choose one mode over others for making a particular trip based on different modal utilities for their different purposes.

Since, a large number of trips are produced and distributed for employment purpose that is $84.54 \%$. As a result, employment is considered as a measure of attraction of different zones. The distance from Savar Pourashava and employment status of different zones are given in Table 13.

Table 13: Distance and employment status of different zones.

\begin{tabular}{|l|c|c|}
\hline Zones & Distance $(\mathrm{km})$ & Employment \\
\hline Motijheel & 29 & 168225 \\
\hline Tejgaon & 22 & 167934 \\
\hline Savar EPZ & 15 & 120000 \\
\hline
\end{tabular}

Source: Banglapedia, 2003 and Field survey, 2006.

A total of 198,017 trips were produced in the study area per day. In gravity model, the distance from study zone to the destination zones, the measure of attractiveness of the destination zones, such as employment and the total trip production from the study area, were considered. By applying this model, it is found that the number of trips distributed among Motijheel, Tejgaon and Savar EPZ were 36673, 63583 and 97761 respectively.

\section{Findings on Modal Choice for Selected Destinations}

\section{Savar to Motijheel}

The respondents of the study area who went from Savar to Motijheel for their employment purpose, bus was the preferable mode compared to taxi cab and auto-rickshaw (CNG) by the majority of respondents, because the travel cost by bus (Tk. 20) was lower than other modes. The cost for taxi cab and auto-rickshaw (CNG) were Tk.180 and Tk.155 respectively (Field Survey, 2006). But the travel time by bus is higher ( 80 minutes) compared to taxi cab and auto-rickshaw (CNG) which take 60 and 70 minutes respectively. The respondents choose the bus considering the lower travel cost that was affordable to respondents. Of the total 36673 trips between these two zones, 36086 trips were made by bus, 330 by auto-rickshaw and 257 by taxi cab.

\section{Savar to Tejgaon}

The respondents preferred bus service to travel from Savar to Tejgaon for their employment purpose, because the cost of bus service was much lower than the cost of any other service. The cost for taxi cab and auto-rickshaw (CNG) were Tk.165 and Tk.140 respectively, where the cost for bus service was Tk.15 only. Of the total 63583 trips between these two zones, 62820 trips were made by bus, 509 by auto-rickshaw and 254 by taxi cab. 


\section{Savar to Savar EPZ}

The bus was also preferable mode by the respondents to travel from Savar to Savar EPZ, because of the lower travel cost by bus that was Tk.10 only. The cost of taxi cab and auto-rickshaw were Tk.105 and Tk.90 respectively. Although the travel time (25 minutes) was higher by bus compared to other services, such as taxi cab and auto-rickshaw. The travel time by both taxi cab and autorickshaw was 20 minutes. Of the total 97761 trips between these two zones, 87203 trips were made by bus, 7136 by auto-rickshaw and 3422 by taxi cab.

\section{Relationship between Land Use and Travel Behavior}

The spatial distribution of activities such as living, working, recreation or education implies that people have to travel. Therefore, the land use configuration is thought to be able to generate particular travel pattern. The demand for travel does not derive its utility from the trip itself, but originates from the need to reach the locations where activities take place (Van Wee, 2002). Land use decisions influence the amount of travel, the geographic location of travel demand and the relative attractiveness and use of various modes of travel. Land use is identified as one of the three major categories of factors that substantially affect travel behavior and demand. The factors that affect travel behavior are shown in Fig. 4.

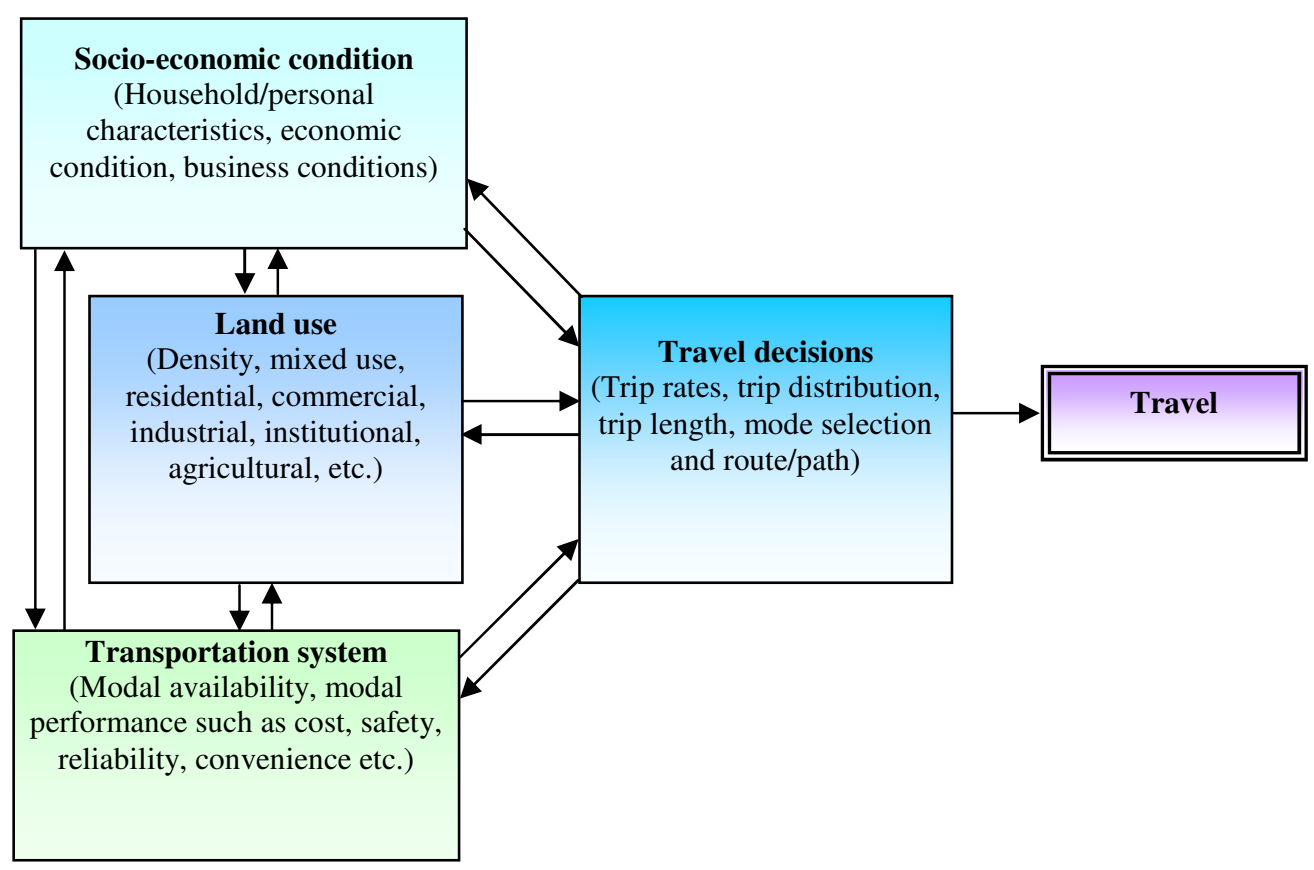

Fig. 4: Factors that affect travel behavior.

\section{Development Density}

Development density is measured with various parameters such as population density, employment, dwelling units, floor area etc (Van Wee, 2002). But in this study, population density is considered as a parameter of development density to establish the relationship between population density and the percentage of trips in different wards of the study area. Basically higher density generates higher rate of trips. Table 14 shows that the percentage of trips increases according to density. The percentage of trips in Wards two, three, five, six and seven are also high because of their higher population density. The range of population density of these Wards is much higher in respect of other Wards of the Pourashava excepting Ward 04 having the highest population density and generating the highest percentage of total trips $(17.89 \%)$. 
Table 14: Ward wise population density and trips.

\begin{tabular}{|c|c|c|}
\hline Ward No. & Density/sq. $\mathrm{km}$. & Percentage of Trips \\
\hline 01 & 7349 & 4.60 \\
\hline 02 & 21710 & 15.30 \\
\hline 03 & 12643 & 11.59 \\
\hline 04 & 32758 & 17.83 \\
\hline 05 & 23877 & 16.80 \\
\hline 06 & 10133 & 10.85 \\
\hline 07 & 8970 & 10.25 \\
\hline 08 & 6254 & 7.28 \\
\hline 09 & 5935 & 5.50 \\
\hline
\end{tabular}

Source: Field Survey, 2006.

\section{Mixed Land Use}

Mixed land use means the mixing of land uses of residential, commercial, industrial, institutional, agricultural, etc. The land use in the study area is generally mixed. As a result, these land uses affect the travel behavior pattern and also the generation of trips of different wards of the study area. Residential land use dominates most of the Wards. It was observed that where agricultural land use is comparatively higher, the trip generation rate is lower, and where commercial, industrial and institutional land uses are found beside the residential land uses, the trip rate is comparatively higher. Table 15 shows the information on mixed land use.

Table 15: Percentage of different land uses of the study area.

\begin{tabular}{|c|c|c|c|c|c|c|c|}
\hline \multirow[b]{2}{*}{$\begin{array}{c}\text { Ward } \\
\text { No. }\end{array}$} & \multicolumn{6}{|c|}{ Percentage of land uses } & \multirow[b]{2}{*}{$\begin{array}{c}\text { Percentage } \\
\text { of trips }\end{array}$} \\
\hline & 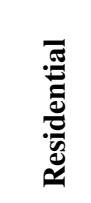 & 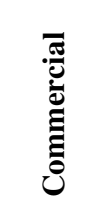 & 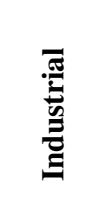 & 预 & 葛 & 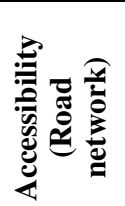 & \\
\hline 01 & 44.18 & -- & -- & 1.39 & 32.76 & 0.49 & 4.60 \\
\hline 02 & 81.44 & 14.78 & 0.29 & 2.32 & -- & 1.17 & 15.30 \\
\hline 03 & 82.98 & 6.39 & 0.41 & 2.30 & 7.39 & 0.53 & 11.59 \\
\hline 04 & 65.40 & 28.46 & -- & 4.80 & -- & 1.34 & 17.83 \\
\hline 05 & 83.07 & 7.82 & -- & 7.56 & -- & 1.55 & 16.80 \\
\hline 06 & 61.12 & 0.47 & 10.39 & 8.25 & 15.73 & 0.62 & 10.85 \\
\hline 07 & 59.53 & 8.11 & 0.24 & 3.09 & 17.47 & 0.67 & 10.25 \\
\hline 08 & 40.66 & 5.97 & 0.92 & 1.92 & 41.22 & 0.58 & 7.28 \\
\hline 09 & 49.24 & -- & 4.38 & 1.13 & 30.96 & 0.70 & 5.50 \\
\hline
\end{tabular}

Source: Field Survey, 2006. 
Table 16: Percentage of destination wise trips and average trip distance for commuters of different Wards.

\begin{tabular}{|c|c|c|c|c|c|c|c|c|}
\hline \multirow{2}{*}{ Ward No. } & \multicolumn{4}{|c|}{ \% of destination wise trips } & \multicolumn{4}{c|}{ Average trip distance (k.m.) } \\
\cline { 2 - 9 } & Savar & Savar EPZ & Motijheel & Tejgaon & Savar & Savar EPZ & Motijheel & Tejgaon \\
\hline 01 & 4.40 & 4.90 & 5.13 & 4.21 & 3.98 & 17.29 & 32.98 & 25.98 \\
\hline 02 & 21.07 & 9.79 & 9.40 & 11.58 & 2.15 & 16.65 & 31.15 & 24.15 \\
\hline 03 & 11.64 & 11.88 & 11.11 & 11.58 & 1.23 & 16.23 & 30.23 & 23.23 \\
\hline 04 & 17.92 & 18.18 & 17.10 & 17.89 & 1.73 & 17.19 & 29.81 & 22.81 \\
\hline 05 & 11.64 & 20.98 & 22.22 & 21.05 & 1.25 & 16.18 & 29.26 & 22.26 \\
\hline 06 & 10.69 & 11.19 & 11.11 & 10.53 & 2.95 & 17.95 & 28.03 & 21.03 \\
\hline 07 & 10.07 & 11.49 & 10.26 & 10.53 & 1.08 & 16.08 & 30.08 & 22.08 \\
\hline 08 & 7.23 & 6.99 & 7.69 & 7.37 & 3.13 & 18.13 & 32.13 & 22.13 \\
\hline 09 & 5.34 & 5.59 & 5.98 & 5.26 & 3.39 & 18.39 & 27.67 & 20.10 \\
\hline
\end{tabular}

Source: Field Survey, 2006.

From Table 16, it is found that in Ward 01, the internal trips are low compared to other Wards of the study area, because there are no commercial and industrial land uses. As a result, majority of the people of Ward 01 travel long distance for different purposes such as business, service, school, work purposes. The average trip distance for commuters of Ward 01 within the area is $3.98 \mathrm{~km}$. For external trips or long distance travel, majority of respondents use bus service because of its cheap fare than the human hauler and auto-rickshaw. The internal trip is high in Ward 02, because of its mixed land use. Rickshaw is the dominating mode of this Ward to travel for internal trip purposes. Internal trip is also high in Ward $04(17.92 \%)$, because of high contribution of commercial $(28.46 \%)$ and institutional $(4.80 \%)$ land uses. In respect of modal choice, rickshaw is also a dominating mode in this ward.

\section{Correlation between Density, Land Use and Trip Ratio}

A strong correlation exists between density and land use with trip generation. To establish a correlation between density, land use and trip ratio, an overall land use scenario of the study area is described and the weights for ward wise population density is determined. Finally, correlation to find out the relationship between density, land use and trip ratio is measured.

The Ward wise weightage index of density and trip ratio are used to measure the correlation between these two variables Figure 5 shows that correlation between weightage index of density and land use and trip ratio are positively correlated. This means that if the density is increased and the land uses are intensive in any ward, the trips generation from this ward is also increased.

\section{Recommendations}

Commuter's modal choice is the key determinants of recent day transport planning. Commuter's always want to get a hold on any mode at any point of time to meet their travel demand. In the study area, not enough modal options are available for them and as a result they face some problems. Some recommendations are made here based on the findings of the study to establish a better transportation system in the Pourashava.

Demand Responsive Mode: As various income groups live in the study area, demand responsive mode should be introduced according to their income level or capacity. The modes could be either public or private. The private organizations play an important role in respect of introducing bus service, as it is the dominating mode to communicate outside of the study area. Beside private company, public bus services such as Bangladesh Road Transport Corporation (BRTC) are also 
operated in the study area. The fare for bus services should be made affordable by all income groups, especially lower and middle income groups.

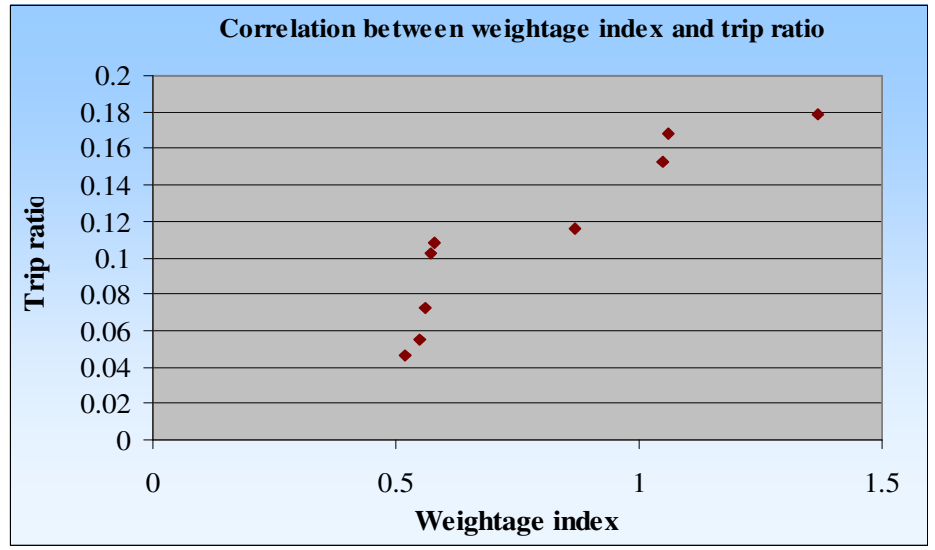

Fig. 5: Correlation between weightage index and trip ratio.

Improved Bus Services: Introducing specialized bus service to communicate with outside areas, is most needed in terms of travel cost and reliability for aged and female people. Public and private bus service should be introduced for aged and female of low, middle and higher income groups and proper facilities should be given to attract them to use these services. Alternatively, the present services system may be maintained by proper regulatory system. The operator must provide services that may meet the demand of the travelers.

To meet the travel demand of the study area, the function of the existing bus services should be improved. It can be done by various ways i.e. by increasing the number of public and private buses in the study area with proper time table so that the users can reach their destinations timely. The seat arrangement of these bus services should be improved to attract passengers to use these services. Moreover, concessionary fare should be provided for children and disabled persons.

Ensurance of Safety and Security: Safety and security should be ensured for the bus users of the study area. The respondents of the study area felt that bus as a mode of travel is unsafe and unsecured because the drivers drive buses recklessly and they do not follow the traffic rules. The safety and security should be ensured by providing proper training of the driver about driving and traffic rules. The physical fitness of the bus service should also be ensured for reducing road accidents. Bangladesh Road Transport Authority (BRTA) should take the responsibility for arranging proper training and also to give the fitness certificate for buses.

Provision of Access of Alternative modes: In the study area, in respect of internal trip purposes, rickshaw is the dominating mode because there are no available options of modes. Tempo and auto-rickshaw such as mishuk should be introduced in the study area as an access of alternative modes. By introducing these modes in the study area, people will be mostly benefited in respect of travel time and cost. The license and route permit should be issued from the license department of the Pourashava.

Provision of Footpath beside the Major Roads: Adequate footpath or sidewalk should be provided beside the roads so that the people who travel short distance (0.5-1.0 kilometers) can easily reach to their destination by walking. But the present scenario of the study area is that the people have to use rickshaw because of absence of adequate footpath in their short distance purposes. The footpath or sidewalk should be made in a proper way so that it attracts the people to use it for short distance traveling by walking. The policy will also reduce the pressure on the use of mode of rickshaw and it will be useful to reduce traffic congestion in the study area. 
Restriction on Land Use: Since land use affect travel behavior, restriction should be imposed on irregular development of land uses. Savar is expanding rapidly and the agricultural lands are continuously converted to residential, commercial and industrial purposes. For this reason, the travel demand will also be increased and the options of various modes will be needed to meet the increasing travel demand. The accessibility should be ensured for different types of modes. It may not be possible to increase or to develop adequate road network, because of the existing development and lack of required spaces. It may also not be possible to introduce various modal options in the rapidly growing Pourashava with increasing population. As a result, if the restrictions are imposed on irregular development, there would be a probability that amount of traffic would be in the forecasted level and it would be easy to provide access for various modes such as rickshaw, tempo and mishuk in the internal areas and the policy will be helpful to meet the travel demand of people of the study area. Before, any development is undertaken, it should be approved from the appropriate authority of the Pourashava.

Construction of New Routes to Meet Future Demand: The increase of trips by different modes in the study area in future will create tremendous pressure on road infrastructure and traffic management system. The existing road network and infrastructure will not meet the demand in future. For this, new routes should be constructed to meet the future demand. It should play an important role to connect the surrounding areas with the study area and ensure better communication within and outside of the study area. The proposed new routes for the study area are shown in Figure 6.

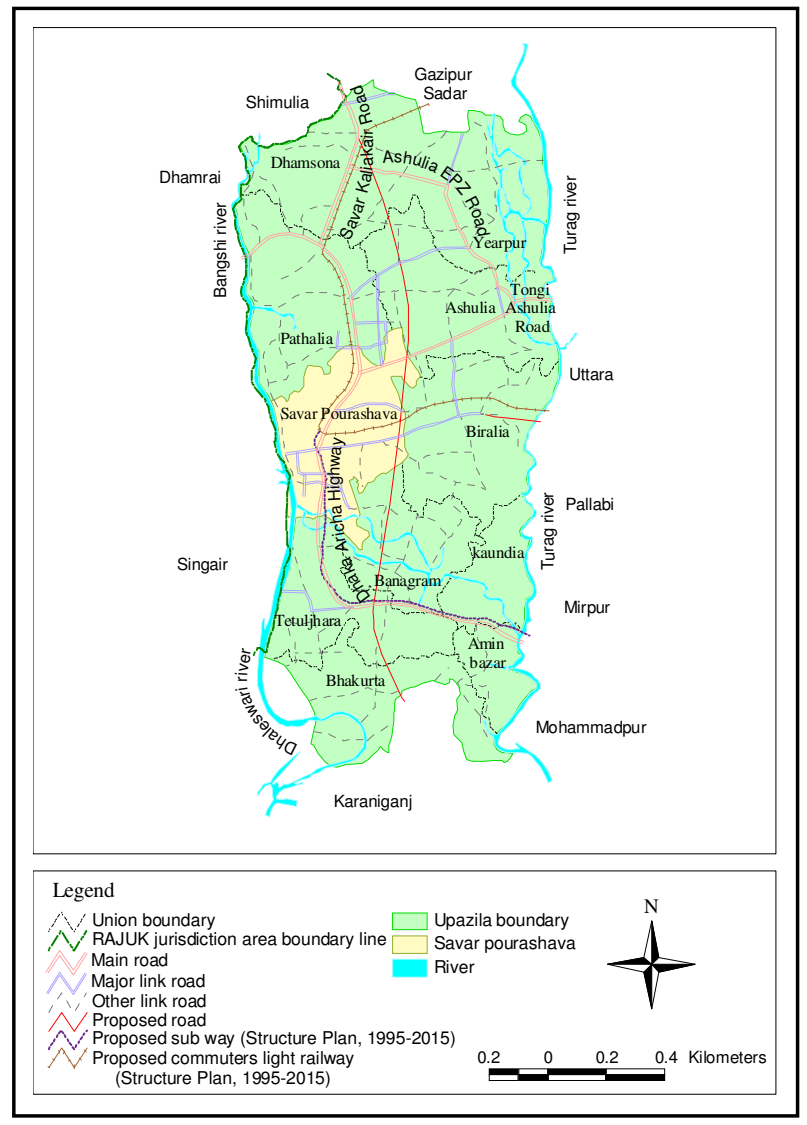

Source: The Mappa Ltd, 2006.

Fig 6: Proposed routes for the study area to meet future demand. 
Beside this, in order to avoid traffic jam in the study area, separate lanes for motorized and nonmotorized vehicles should be provided. The licensing system and route permit should also be controlled by the authority of Savar Pourashava in order to reduce illegal growth of vehicles especially the rickshaw. The width of some major road should be expanded for easy access of vehicles. Footpath should be provided for the pedestrian movement besides the major roads. Land use restriction should be imposed strictly in order to avoid the haphazard growth of vehicle stands in the study area. All of these policies may play an important role to reduce traffic congestion and loss of travel time in the study area.

\section{Conclusion}

Savar is well communicated by road transport system consisting of motorized and non-motorized modes. The modal choice by residents varies from each other depending on demographic and socio-economic characteristics and suitability of different transport modes. However, the quality of available modal services including bus service is not good. It is expected that the recommendations proposed in the research may provide better solution to the existing transportation problems at Savar Pourashava and improve the options for commuters. There should be a continuous assessment of the changes in demand of modes and responses thereby to maintain the reliability of the system. It is expected that this research will be of some use in this regard.

Note: The article is based on a undergraduate thesis conducted in the Department of Urban and Regional Planning at Jahangirnagar University.

\section{References}

Acker, V.V. and Witlox, F. 2005. Exploring The Relationship Between Land-Use System And Travel Behavior, Krijgslaan: Ghent University.

Ara, H. 1983. "Socio-Economic Correlates of Urban Travel Pattern: A Study in Dhaka City" unpublished master's thesis, Department of Urban and Regional Planning, BUET, Dhaka.

Bagley, M.N. and Mokhtarian, P.L. 2002. "The Impact of Residential Neigbhorhood Type on Travel Behavior: A Structural Equations Modeling Approach” Annals of Regional Science 36 279-297.

Banglapedia, 2003. "National Encyclopedia of Bangladesh”, Dhaka: Asiatic Society of Bangladesh, 7 92-93.

Barnes, G. and Davis, G. 2001. Land Use and Travel Choices in the Twin Cities 1958-1990, Center for Transportation Studies, University of Minnesota.

Bhattacharjee, D. 1994. "Modal Choice Analysis and Modelling for Cities with MRT: Case Studies on Singapore and Calcutta" unpublished M. Eng. thesis, Asian Institute of Technology, Bangkok, Thailand.

Bruton, M. J. 1975. Introduction to Transportation Planning, London: Hutchinson,

Cracknel, K. 2001. Urban Mobility and Livable Cities for Future, Sydney: McGraw Hill.

Dieleman, F.M., Dijst, M., and Burghouwt, G. 2002. "Urban Form and Travel Behaviour: Micro-level Household Attributes and Residential Context" Urban Studies 39 (3) 507-527.

Friedman, B., Gordon, S.P., and Peers, J.B. 1994. "Effect of Neotraditional Neighborhood Design on Travel Characteristics" Transportation Research Record 1466 63-70.

Giuliano, G., and Small, K.A. 1993. "Is the Journey to Work Explained by Urban Structure ?" Urban Studies 30 1485-1500.

GOB, UNCHS and UNDP, 1993. "Bangladesh Urban and Shelter Sector Review, A Draft Report" Government of Bangladesh.

Hallewell, S. 1983. "Development Planning and Public Transport Design: A Fundamental Relationship" Planning for Public Transport in Town and Country Planning, London.

Kanafani, A. 1983. Transportation Demand Analysis, New York: McGraw-Hill. 
Lee, D. 1989. Methods in Urban Transport Planning, New York: Paul Chapman.

Moinuddin.G. and Fouzdar.J.A, 2005. "Commuters Modal Choice: A Critical Review on Conceptual Issues and Empirical Propositions" Journal of The Jahangirnagar Review, Vol. 38, pp. 91-104.

Naess, P. 2005. "Residential Location Affects Travel Behavior - But How and Why ? The Case of Copenhagen Metropolitan Area" Progress in Planning, Vol. 63, 167-257.

Rahman, S. M. 2006. "Planning, the Growth of Peri-urban Settlement: A case study on Savar Pourashava", unpublished thesis, Department of Urban and Regional Planning, Jahangirnagar University, Dhaka.

Schwanen, T., and Mokhtarian, P.L. 2005a. "What Affects Commute Mode Choice: Neighbourhood Physical Structure or Preferences Toward Neighbourhoods?" Journal of Transport Geography, 13 83-99.

Stead, D. 2001. "Relationships Between Land Use, Socioeconomic Factors and Travel Patterns in Britain" Environment and Planning, Vol. 28, 499-528.

Van Wee, B. 2002. "Land Use and Transport: Research and Policy Challenges" Journal of Transport Geography, Vol. 10, 259-271.

Witlox, F. and Acker, V.V. 2005. "Exploring the Relationship between Land-use System and Travel Behavior" Department of Geography, Ghent University, Krijgslaan 281-S8.

Zhang, M. 2004. "The Role of Land Use in Travel Mode Choice" Journal of the American Planning Association, Vol. 70(3). 